\title{
Biological Validation of the Free Software RhizoVision Explorer to Determine Root Parameters in Horticultural Crops
}

Guillermo Ignacio Perez ( $\nabla$ gip@live.com.ar)

CONICET: Consejo Nacional de Investigaciones Cientificas y Tecnicas https://orcid.org/0000-00034338-8247

María Micaela Stoffel

Claudio Javier Baroni

María Eugenia Maina

Lucas Damián Daurelio

Fernando Felipe Muñoz

\section{Research Article}

Keywords: Root growth parameters, Free software, Selenium, Horticultural crops

Posted Date: March 7th, 2022

DOI: https://doi.org/10.21203/rs.3.rs-1389627/v1

License: (9) (1) This work is licensed under a Creative Commons Attribution 4.0 International License.

Read Full License 


\section{Abstract \\ Aims}

The objectives of this work were to compare the degree of fit between WinRhizo (WR) and RhizoVision Explorer (RVE), and validated the utility of RVE in biological assays.

\section{Methods}

Seedlings of lettuce (Lactuca sativa L. var. Grand rapid), broccoli (Brassica oleracea L. var. italica Plenck $\mathrm{H}$. Belstar) and bell pepper (Capsicum annuum L. H. Floridor) were irrigated with different concentrations of sodium selenate and sodium selenite. Scanned images of the roots were obtained and analyzed with WR and RVE.

\section{Results}

Results showed that mean bias error (MBE) values for total root length and average diameter of roots indicate an overestimation of RVE with respect to WR, while the opposite is true for the number of root tips. In bell pepper, the highest values of the root mean square error (RSME) were observed with respect to the other two crops. Furthermore, there were significant differences $(P<.0001)$ between the values measured by RVE and WR for the 3 crops. For most of the crops and parameters evaluated there was a high linear regression coefficient between the programs. Similarly, linear correlation coefficient was high in all three crops for most of the root diameter classes evaluated. The two programs allowed finding similar significant differences for the selenium treatments.

\section{Conclusions}

RVE allowed to contrast and analyze the biological effect of different types of treatments on the roots.

\section{Introduction}

The root system of plants has multiple functions as structural stability in the soil or substrate, the acquisition of water and nutrients, and the interaction in the rhizosphere zone with other living organisms (Griffiths et al. 2021b; Lynch 1994; Lynch et al. 2001). Root system architecture (RSA) varies in shape and spatial arrangement throughout the plant growth cycle, affecting the interception and uptake of soil resources. The configuration of the RSA is determined by the interaction of genetic and environmental factors, which affect crop productivity and yield (Bucksch et al. 2014; Griffiths et al. 2021b; Lynch 1995; Osmont et al. 2007; Rogers and Benfey 2015). 
Thus, it is important to measure how and how much environmental changes affect certain key parameters of root growth. These are related to their functional significance per se and to each other when they are correlated. Some of them are simple morphological parameters such as: root length (mm) and area $\left(\mathrm{mm}^{2}\right)$, root number or root diameter. While others are composite parameters such as specific root length (SRL: $\mathrm{mm} \mathrm{g}^{-1}$ ) or those related to root activity. Whether simple or composite parameters, each will have significance in the performance of the crop in the medium in which it grows (Atkinson 2000; Himmelbauer et al. 2004a).

In order to begin to understand RSA, the first step is to obtain root images and then extract the architectural information. The ways to obtain images are variable in a wide range of array of experimental systems. For example from soil cores, classical imaging using flat-bed scanners or cameras, in hydroponics or aeroponics, rhizotrons, gel plates or gellan gum (Lobet et al. 2011). The resolution of digital images with the automated analysis, will allow a repeatable extraction of a much richer set of measurements (Pound et al. 2013). Images must be analyzed efficiently and objectively. There are different software programs that vary in their degree of automatization (Lobet et al. 2011). Several of them apply a sequence of filters to eliminate pixels that aren't considered root material, and finally group those as roots (Pound et al. 2013). The most common techniques are the image smoothing, image thresholding, and skeletonization (Atkinson et al. 2019; Pound et al. 2013).

WinRHIZO'M - WR - (Regent Instruments Inc., Quebec, Canada, 2000) is one of the best-known software programs to measure morphological parameters in root images (Arsenault et al. 1995; Pang et al. 2011; Wang and Zhang 2009). This is automated and operates with 256 levels grayscale images in TIFF file format. These are converted into threshold (binary) and skeleton images; thresholding procedures provides separation of the root from the background pixels. Skeletonization result in a transformation of one-pixel thick line overlaying objects within the image. Additionally, the program detects overlapping parts and takes them into account when calculating root parameters (Himmelbauer et al. 2004b).

It is valuable to find an alternative software to WinRHIZO ${ }^{\text {TM }}$, free, automated, and, reliable and reproducible in the measurements. The perform of many free software programs is good in root images areas of higher quality. In areas of lower quality the root overlap is higher, requiring semi-automated or manual tracing methods, in consequence, that implies a greater investment of time (Lobet et al. 2011).

RhizoVision Explorer - RVE - (@ Noble Research Institute, LLC) is a recently free automated software. It is open source and released under a modified GPL 3 license with an additional indemnification clause (Seethepalli and York 2020). This program uses images from a flatbed scanner or camera, with an interactive window for the user. Furthermore, the parameters selections influence in the segmentation and the final result of the image, with a simple and intuitive interface. RVE derives from a previous software called RhizoVision Analyzer (RVA) using to analyze excavated root crowns (Mattupalli et al. 2018; Seethepalli et al. 2020). RVE, unlike RVA, was developed for more general purposes, for whole roots or for broken roots. RVE has been used for a variety of purposes in different crops (Delory et al. 2021; Griffiths et al. 2021a; Griffiths et al. 2021b; Guo et al. 2020; Han et al. 2020). 
Nowadays, there is a gap in reliable and free software programs, with reproducible data in the analysis of root images. It is expected, that the results are a least in the same amount or proportion, and useful in biological assays. Thus, we propose to RVE as an alternative for the reliable growth parameters measurement of root images.

In the present work, we compared the adjustment of calculated morphological parameters in three different horticultural root crops between the commercial software WR and the free software RVE. It is known that selenium salts have various effects on the growth parameters of different crops under certain growing conditions (Balakhnina and Nadezhkina 2017; Gupta and Gupta 2017; Irmak 2017; Liu et al. 2004; Mroczek-Zdyrska and Wójcik 2012; Naseem et al. 2021). Secondly, we evaluated at a biological level the effect of different selenium salts treatments with both software programs in the same set of root images.

\section{Materials And Methods}

Plant growth conditions and treatments application

Lettuce (Lactuca sativa L. var. Grand rapid), bell pepper (Capsicum annuum L. H. Floridor), and broccoli (Brassica oleracea L. var. italica Plenck H. Belstar) roots, corresponding to seedlings of uniform size grown in multi-layer trays with commercial substrate and subjected to continuous irrigation with $50 \%$ Hoagland's nutrient solution (Hoagland and Arnon 1950) with five different concentrations $(3,6,12,24$ and $48 \mu \mathrm{M})$ of two species of selenium, sodium selenite $\left(\mathrm{Na}_{2} \mathrm{SeO}_{3}\right)$ and sodium selenate $\left(\mathrm{Na}_{2} \mathrm{SeO}_{4}\right)$ were evaluated, as well as the control ( $0 \mu \mathrm{M}$ selenium $)$ with a total of eleven treatments. We used 36 seedlings of each selenium treatment, and bell pepper seedlings were treated only with sodium selenate. Seventytwo seedlings of lettuce and broccoli, and 36 seedlings of bell pepperwere harvested, the roots were separated from the shoot and then completely washed with running water to remove any debris or substrate residue.

Seedlings were cultivated in a plant chamber for 20 days under the following conditions: red/white led light, with a photoperiod of $16 \mathrm{~h}$ day/night, with a constant temperature of $20 \pm 2^{\circ} \mathrm{C}$ and the relative humidity was $60 \pm 15 \%$. All the assays were performed in the Laboratorio de Investigaciones de Fisiología y Biología Vegetal (LIFiBVe), Facultad de Ciencias Agrarias de la Universidad Nacional del Litoral/ ICiAgro Litoral (CONICET).

Image acquisition and setting values

The roots of each crop were scanned on an Epson Expression 11000XL flatbed scanner with a transparency unit (overhead light), using WinRHIZO ${ }^{\text {TM }}$ root-scanning equipment and software (WinRHIZO Pro 2013d, Regent Instruments, Quebec, Canada) with a resolution of $400 \mathrm{DPI}$, in grayscale and saved in TIFF format. We also processed the same images with the free software RhizoVision Explorer (৫) Noble Research Institute, LLC). RVE setting values for each crop are presented on the Table 1: 
Table 1

Setting values of RVE.

\begin{tabular}{|lllll|}
\hline Crop & $\begin{array}{l}\text { Thresholding } \\
\text { level }\end{array}$ & $\begin{array}{l}\text { Filter } \\
\text { Particles } \\
(\mathbf{m m})\end{array}$ & Root pruning threshold & $\begin{array}{l}\text { Diameter } \\
\text { classes } \\
(\mathbf{m m})\end{array}$ \\
\hline Lettuce & 210 & 1 & 1 & 0 to 2.5 by 0.5 \\
\hline Broccoli & 200 & 1 & 1 & 0 to 4 by 0.5 \\
\hline Bell pepper & 168 & 100 & 1 & 0 to $>4.5$ by 0.5 \\
\hline
\end{tabular}

Root parameters

Root parameters calculated with the two software programs were: number of root tips (RT), total root length (TRL) in $\mathrm{mm}$, average diameter (AD) in $\mathrm{mm}$, and root length $(\mathrm{mm})$ in diameter class. The diameter classes were the same in both software programs.

\section{Statistical analysis}

We used the coefficient of correlation ( $\rho$ ) and linear regression ( $\beta$ ) analysis Slope ( $\alpha$ ) and coefficient of determination $\left(R^{2}\right)$ of the linear regression was used to compare paired measurements between WR and RVE-estimated data. In order to quantify the differences in the measurements between WR and RVEestimated data we used different metrics such as mean bias error (MBE) and root mean square error (RMSE). Student $t$ test for paired samples were used to check if the two software programs measure in the same way. The data will be analyzed by an analysis of variance (ANOVA) and the means will be compared by Fisher's Least Significant Difference (LSD) test with a significance level of $P<0.05$ to evaluate the efficacy of RVE to measure biological aspects of the effects of selenium treatments in root parameters of the crops evaluated. Statistical analysis were done with software INFOSTAT (Di Rienzo et al. 2008).

\section{Results}

Comparison between RVE and WR for the morphological parameters evaluated.

Table 2 shows that there was a strong correlation between the values measured by RVE and WR for total root length (TRL). Bell pepper had the highest values of RMSE $(534.04 \mathrm{~mm})$ and the highest overestimation in the values measured by RVE in relation to WR (MBE $494.19 \mathrm{~mm}$ ), while in lettuce were observed the lowest values of RMSE $(60.21 \mathrm{~mm})$ and MBE $(47.54 \mathrm{~mm})$. There were significant differences $(P<.0001)$ between the values measured by RVE and WR for the 3 crops.

Table 2 Coefficient of correlation ( $r$, RMSE and MBE values, $P$-value of Student $t$ test for paired samples between RhizoVision Explorer and WinRHIZO-estimated total root length, average diameter, and number 
of root tips in each crop.

\begin{tabular}{|llllll|}
\hline & \multicolumn{1}{l}{ r } & RMSE $(\mathrm{mm})$ & MBE $(\mathrm{mm})$ & & Crop \\
\hline Total & 1.00 & 60.21 & 47.54 & $P<.0001$ & Lettuce \\
\cline { 2 - 6 } root & 1.00 & 109.98 & 92.62 & $P<.0001$ & Broccoli \\
length & 0.97 & 534.04 & 494.19 & $P<.0001$ & Bell pepper \\
\hline Average & 0.89 & 0.07 & 0.06 & $P<.0001$ & Lettuce \\
\cline { 2 - 6 } diameter & 0.88 & 0.12 & 0.11 & $P<.0001$ & Broccoli \\
\cline { 2 - 6 } & 0.97 & 0.17 & 0.17 & $P<.0001$ & Bell pepper \\
Root & 0.87 & 16.07 & -3.33 & $P=.0782$ & Lettuce \\
\cline { 2 - 6 } tips & 0.73 & 106.87 & -46.65 & $P=.0001$ & Broccoli \\
\cline { 2 - 6 } & 0.73 & 467.58 & -348.42 & $P<.0001$ & Bell pepper \\
\hline the number of datasets is 180. & & & \\
\hline
\end{tabular}

Linear regression coefficients for TRL in the 3 crops were very high as shown in Fig. 1, with slope values close to 1, overestimating the values measured by RVE in relation to WR in the 3 crops as shown in the slopes of the linear regression equations.

In terms of average root diameter (AD), the correlation coefficient was lower than that calculated for TRL, except for bell pepper, however, the values were high. Likewise, RVE in relation to WR presented the same tendency as in TRL for RSME and MBE, being higher for bell pepper (RSME $0.17 \mathrm{~mm}$; MBE $0.17 \mathrm{~mm}$ ) and lower for lettuce (RSME $0.07 \mathrm{~mm}$; MBE $0.06 \mathrm{~mm}$ ), overestimating the values measured in all crops by RVE. Similarly, with TRL, there were significant differences $(P<.0001)$ between what was measured by RVE and WR for the 3 crops (Table 2).

Linear regression coefficients for $A D$ were very high for bell pepper, and were high for lettuce and broccoli as shown in Fig. 2. The best fit to the linear regression line was observed in lettuce with a slope value close to 1. In contrast, in broccoli and bell pepper the slope values of the linear regression equations were greater than 1, indicating that the values measured with RVE were overestimated by those measured with WR.

Correlation coefficient for root tips number (RT) between RVE and WR was very high only for lettuce. For the parameters measured in the 3 crops, RSME and MBE presented the same trend in decreasing order for bell pepper, broccoli and lettuce, but contrary to what was observed for TRL and AD, RVE underestimated the values measured by WR according to MBE values. Significant differences $(P<.0001)$ between RVE and WR measurements were observed for broccoli and bell pepper, but not for lettuce $(P=.0782)$ (Table 2). 
Figure 3 shows that the linear regression coefficient and the slope fit was high only for lettuce, but not for bell pepper and broccoli where the $\mathrm{R}^{2}$ values were very low, and RVE underestimated that measured by WR as shown in the slopes of the linear regression equations.

Table 3 shows that for all evaluated diameter classes of TRL in lettuce roots, there were very high correlation coefficients between RVE and WR measurements. On the contrary, in broccoli and bell pepper when increasing the diameter within each range, the values of correlation coefficients were decreasing from very high to low values for high diameter classes, particularly in broccoli and bell pepperfor the 3.5$4 \mathrm{~mm}$ diameter class, where $\mathrm{r} 0.41$ and r 0.6 , respectively.

Table 3

Coefficient of correlation ( $r$ ) between RhizoVision Explorerestimated and WinRHIZO-estimated root length $(\mathrm{mm})$ in each diameter classes $(\mathrm{mm})$.

\begin{tabular}{|llll|}
\hline $\begin{array}{l}\text { Diameter } \\
\text { classes }(\mathbf{m m})\end{array}$ & $\begin{array}{l}\text { Lettuce } \\
(\mathbf{n}=72)\end{array}$ & $\begin{array}{l}\text { Broccoli } \\
(\mathbf{n}=72)\end{array}$ & Bell pepper $(\mathbf{n}=\mathbf{3 6})$ \\
\hline $0-0.5$ & 1.00 & 0.99 & 0.98 \\
$0.5-1$ & 0.95 & 0.97 & 0.97 \\
\hline $1-1.5$ & 0.91 & 0.83 & 0.97 \\
\hline $1.5-2$ & 0.90 & 0.81 & 0.95 \\
\hline $2-2.5$ & 1.00 & 0.71 & 0.95 \\
\hline $2.5-3$ & ND & 0.68 & 0.82 \\
\hline $3-3.5$ & ND & 0.68 & 0.71 \\
\hline $3.5-4$ & ND & 0.60 & 0.41 \\
\hline $4-4.5$ & ND & ND & 0.66 \\
\hline$>4.5$ & ND & ND & 0.70 \\
\hline the number of datasets is 180. nd: no data. & \\
\hline
\end{tabular}

Validation of the efficacy of RVE to measure biological aspects

Results obtained from the processing of images of lettuce roots treated with different concentrations of selenite showed that TRL (RVE $P<.0001$; WR $P<.0001)$ was significantly lower than the control $(0 \mu \mathrm{M} \mathrm{Se})$ in the 12, 24 and $48 \mu \mathrm{M}$ treatments, similarly for RT (RVE $P<.0001$; WR $P<.0001$ ) the control and the 3 $\mu \mathrm{M}$ treatment were significantly different from the rest of the treatments (Table 4 ). In the case of $A D$, there were only significant differences between treatments when roots were measured with WR (RVE $P=.1300$; 
WR $P=.0453)$. With selenate, the TRL parameter was significantly lower in comparison to the control in the 6, 24 and $48 \mu \mathrm{M}$ treatments with $\operatorname{RVE}(P=.0007)$ and WR $(P=.0007)$. On the other hand, for RT with the values obtained with WR $(P=.0009)$ only the $48 \mu \mathrm{M}$ treatment was significantly lower than the control, in contrast to the values calculated with $\operatorname{RVE}(P=.0067)$ where this treatment and the $24 \mu \mathrm{M}$ treatment had significant differences in relation to the control. Finally, in terms of $A D$, the differences were significantly lower than the control with the 24 and $48 \mu \mathrm{M}$ treatments when the roots were processed with $\operatorname{RVE}(P<.0001)$, and with the $3,6,24$ and $48 \mu \mathrm{M}$ treatments when WR was used $(P<.0001)$.

Table 4

Arrangement of selenite and selenate treatments $(0,3,6,12,24$ and $48 \mu \mathrm{M})$ according to the LSD Fisher values for the parameters evaluated in lettuce.

\begin{tabular}{|c|c|c|c|c|c|c|c|c|}
\hline \multirow[t]{2}{*}{ Parameter } & \multicolumn{4}{|c|}{ Selenite treatment $(\mu \mathrm{M})$} & \multicolumn{4}{|c|}{ Selenate treatment $(\mu \mathrm{M})$} \\
\hline & RVE & & WR & & RVE & & WR & \\
\hline \multirow{6}{*}{$\begin{array}{l}\text { Total root } \\
\text { length }\end{array}$} & \multirow[t]{6}{*}{$P<.0001$} & 48 & \multirow[t]{6}{*}{$P<.0001$} & 48 & \multirow[t]{6}{*}{$P=.0007$} & 48 & \multirow[t]{6}{*}{$P=.0007$} & 48 \\
\hline & & 24 & & 24 & & 24 & & 24 \\
\hline & & 12 & & 12 & & 6 & & 6 \\
\hline & & 6 & & 6 & & 12 & & 12 \\
\hline & & 3 & & 3 & & 3 & & 3 \\
\hline & & 0 & & 0 & & 0 & & 0 \\
\hline \multirow{6}{*}{$\begin{array}{l}\text { Root } \\
\text { tips }\end{array}$} & \multirow[t]{6}{*}{$P<.0001$} & 48 & \multirow[t]{6}{*}{$P<.0001$} & 48 & \multirow[t]{6}{*}{$P=.0009$} & 48 & \multirow[t]{6}{*}{$P=.0067$} & 48 \\
\hline & & 24 & & 24 & & 24 & & 24 \\
\hline & & 12 & & 12 & & 3 & & 3 \\
\hline & & 6 & & 6 & & 6 & & 6 \\
\hline & & 3 & & 0 & & 12 & & 0 \\
\hline & & 0 & & 3 & & 0 & & 12 \\
\hline \multirow{6}{*}{$\begin{array}{l}\text { Average } \\
\text { diameter }\end{array}$} & \multirow[t]{6}{*}{$P=.1300$} & 6 & \multirow[t]{6}{*}{$P=.0453$} & 6 & \multirow[t]{6}{*}{$P<.0001$} & 0 & \multirow[t]{6}{*}{$P<.0001$} & 0 \\
\hline & & 12 & & 12 & & 12 & & 12 \\
\hline & & 0 & & 24 & & 3 & & 3 \\
\hline & & 24 & & 48 & & 6 & & 6 \\
\hline & & 48 & & 0 & & 24 & & 24 \\
\hline & & 3 & & 3 & & 48 & & 48 \\
\hline
\end{tabular}


When the effect of different concentrations of selenite salts in broccoli was evaluated with the two measurement methods (Table 5), it was observed that TRL was significantly lower in relation to the control $(0 \mu \mathrm{M} \mathrm{Se})$ in the 48,24 and $12 \mu \mathrm{M}$ treatments when the roots were processed with $\operatorname{RVE}(P<.0001)$ and in 48 and $24 \mu \mathrm{M}$ when they were processed with WR $(P<.0001)$. In RT there were significant differences with the control only for values obtained from images processed with RVE $(P<.0001)$ for the 48 and $6 \mu \mathrm{M}$ treatments, being lower and higher values, respectively, versus WR $(P=.1327)$. Regarding the AD parameter, both the values obtained with RVE $(P<.0001)$ and those obtained with WR $(P<.0001)$ were significantly higher for the 3 and $48 \mu \mathrm{M}$ treatments in relation to the control. With selenate salts for TRL, all treatments were significantly lower in relation to the control for the values obtained with RVE $(P$ $<.0001)$ and with WR $(P<.0001)$. The same occurred with RT for RVE $(P<.0001)$, but not for WR $(P$ $<.0001)$, where the $6 \mu \mathrm{M}$ treatment did not differ from the control treatment. Finally, for AD there were no significant differences between treatments with RVE $(P=.0594)$, but there were significant differences with WR $(P=.0031)$ where the 3 and $48 \mu \mathrm{M}$ treatments were significantly higher than the control. 
Table 5

Arrangement of selenite and selenate treatments $(0,3,6,12,24$ and $48 \mu \mathrm{M})$ according to the LSD Fisher values for the parameters evaluated in broccoli.

\begin{tabular}{|c|c|c|c|c|c|c|c|c|}
\hline \multirow[t]{2}{*}{ Parameter } & \multicolumn{4}{|c|}{ Selenite treatment $(\mu \mathrm{M})$} & \multicolumn{4}{|c|}{ Selenate treatment $(\mu \mathrm{M})$} \\
\hline & \multicolumn{2}{|l|}{ RVE } & \multicolumn{2}{|l|}{ WR } & \multicolumn{2}{|l|}{ RVE } & \multicolumn{2}{|l|}{ WR } \\
\hline \multirow{6}{*}{$\begin{array}{l}\text { Total root } \\
\text { length }\end{array}$} & \multirow[t]{6}{*}{$P<.0001$} & 48 & \multirow[t]{6}{*}{$P<.0001$} & 48 & \multirow[t]{6}{*}{$P<.0001$} & 48 & \multirow[t]{6}{*}{$P<.0001$} & 48 \\
\hline & & 24 & & 24 & & 24 & & 24 \\
\hline & & 12 & & 12 & & 12 & & 12 \\
\hline & & 3 & & 3 & & 3 & & 3 \\
\hline & & 6 & & 0 & & 6 & & 6 \\
\hline & & 0 & & 6 & & 0 & & 0 \\
\hline \multirow{6}{*}{$\begin{array}{l}\text { Root } \\
\text { tips }\end{array}$} & \multirow[t]{6}{*}{$P=.0010$} & 48 & \multirow[t]{6}{*}{$P=.1327$} & 48 & \multirow[t]{6}{*}{$P<.0001$} & 48 & \multirow[t]{6}{*}{$P<.0001$} & 48 \\
\hline & & 24 & & 24 & & 3 & & 3 \\
\hline & & 12 & & 12 & & 24 & & 24 \\
\hline & & 0 & & 6 & & 12 & & 12 \\
\hline & & 3 & & 0 & & 6 & & 6 \\
\hline & & 6 & & 3 & & 0 & & 0 \\
\hline \multirow{6}{*}{$\begin{array}{l}\text { Average } \\
\text { diameter }\end{array}$} & \multirow[t]{6}{*}{$P<.0001$} & 0 & \multirow[t]{6}{*}{$P<.0001$} & 12 & \multirow[t]{6}{*}{$P=.0594$} & 6 & \multirow[t]{6}{*}{$P=.0031$} & 6 \\
\hline & & 12 & & 0 & & 12 & & 0 \\
\hline & & 6 & & 6 & & 24 & & 12 \\
\hline & & 24 & & 24 & & 3 & & 3 \\
\hline & & 3 & & 3 & & 48 & & 48 \\
\hline & & 48 & & 48 & & 0 & & 24 \\
\hline
\end{tabular}

In the case of bell pepper, only the effect of selenate salts was evaluated. The TRL values were significant for both measurement methods, observing that only the $48 \mu \mathrm{M}$ treatment was significantly lower than the control with $\operatorname{RVE}(P=.0003)$, occurring the same with WR $(P=.0001)$, but, in turn also the values of the $6 \mu \mathrm{M}$ treatment were statistically higher. For RT, there were no significant differences between treatments with $\operatorname{RVE}(P=.0356)$, but with WR $(P<.0001)$, where the $6 \mu \mathrm{M}$ treatment was 
significantly superior to the control. For AD, the values obtained with RVE $(P=.002)$ and with WR $(P$ $=.0024)$ for the different treatments had significant differences, being higher for the $24 \mu \mathrm{M}$ treatment in relation to the control (Table 6).

Table 6

Arrangement of selenate treatments $(0,3,6,12,24$ and $48 \mu \mathrm{M})$ according to the LSD Fisher values for the parameters evaluated in bell pepper.

\begin{tabular}{|c|c|c|c|c|}
\hline \multirow{4}{*}{$\begin{array}{l}\text { Parameter } \\
\text { Total root } \\
\text { length }\end{array}$} & \multicolumn{4}{|c|}{ Selenate treatment $(\mu \mathrm{M})$} \\
\hline & \multicolumn{2}{|l|}{ RVE } & \multicolumn{2}{|c|}{ WR } \\
\hline & \multirow[t]{6}{*}{$P=.0003$} & 48 & \multirow[t]{6}{*}{$P=.0001$} & 48 \\
\hline & & 3 & & 3 \\
\hline & & 24 & & 24 \\
\hline & & 0 & & 12 \\
\hline & & 12 & & 0 \\
\hline & & 6 & & 6 \\
\hline \multirow{6}{*}{$\begin{array}{l}\text { Root } \\
\text { tips }\end{array}$} & \multirow[t]{6}{*}{$P=.0356$} & 48 & \multirow[t]{6}{*}{$P<.0001$} & 48 \\
\hline & & 3 & & 3 \\
\hline & & 24 & & 0 \\
\hline & & 0 & & 12 \\
\hline & & 12 & & 24 \\
\hline & & 6 & & 6 \\
\hline \multirow{6}{*}{$\begin{array}{l}\text { Average } \\
\text { diameter }\end{array}$} & \multirow[t]{6}{*}{$P=.002$} & 48 & \multirow[t]{6}{*}{$P=.0024$} & 48 \\
\hline & & 6 & & 6 \\
\hline & & 0 & & 0 \\
\hline & & 12 & & 12 \\
\hline & & 3 & & 3 \\
\hline & & 24 & & 24 \\
\hline
\end{tabular}

\section{Discussion}


The current study found that in all parameters evaluated (TRL, RT and AD) for the 3 crops, the values measured by RVE in relation to those measured by WR had a very high correlation coefficient, with the exception of the RT parameter in broccoli and bell pepper where the correlation was high. For the three variables measured, the RMSE value was higher in peppers and lower in lettuce. The MBE values allowed observing that on average the values measured by RVE compared to WR were overestimated for TRL and $A D$, and underestimated for RT, coinciding with the findings of Seethepalli and York (2020).

Correlation coefficients for the different diameter classes had high to very high values, with the exception of the 3.5-4 mm diameter class in bell pepper and broccoli. Nevertheless, for most of the diameter classes it was not necessary to use conversion factors between RVE and WR, as observed in previous works (Tajima and Kato 2011; 2013), where the authors used a conversion factor of $2 / 3$ between WR and Image J for diameter classes below $0.5 \mathrm{~mm}$.

For lettuce crop roots, in most of the treatments evaluated with the different selenium salts in all parameters, the values obtained with both measurement methods allowed finding very similar significant differences between treatments, with the exception of $A D$ for selenate salts, where the statistic applied to the values obtained with RVE, discriminated a smaller number of treatments with significant differences with respect to the control. In the case of the analysis of the effect of selenium salts treatments in broccoli roots on the evaluated parameters, the degree of statistical coincidence between the measurement methods was lower than for lettuce. However, for some parameters and concentration and type of selenium salt, the difference between one and another measurement method was only at the level of 1 treatment with or without statistical difference in relation to the control, which would imply in this case that the level of sensitivity of one or another method would influence the selection or discarding of a treatment and the effect of the treatment on the parameters evaluated. In particular, is the case of the selenite salts treatments in the RT parameter, the values obtained with RVE allowed that the statistic found significant differences with respect to the control, while the same did not occur with WR. In bell pepper, the values obtained with RVE and WR for AD, allowed that the statistic used found similarities in the degree of significance between the treatments evaluated for selenate salts and significant differences in relation to the control. In TRL, although there were significant differences between treatments when we measured with both methods, the values obtained with WR allowed to the statistics to find significant differences in relation to the control for more than 1 treatment. When the values obtained with RVE were analyzed, the statistic didn't find significant differences between treatments, while the contrary occurred with WR. Se at trace concentrations allows normal growth and development, at moderate concentrations it can be stored for homeostatic functions, and at high concentrations it can have toxic effects on plants (Feng et al. 2013; Gupta and Gupta 2017; Handa et al. 2016; Hawrylak-Nowak et al. 2015; Kaur et al. 2014). Some studies have shown that the effect of Se salts is manifested by an improvement in the partitioning of photoassimilates to the roots, an increase in the fresh and/or dry weight of the roots (Balakhnina and Nadezhkina 2017; Haghighi et al. 2019; Mroczek-Zdyrska and Wójcik 2012; Naseem et al. 2021; Shekari et al. 2016). 


\section{Conclusion}

Despite the results obtained, although they do not show that the 2 software programs measure exactly the same thing, the degree of adjustment found between them is high, also, it was possible to contrast and analyze the biological effect of different types of treatments on the roots, so the use of RVE is recommended as an alternative to other software for the measurement of root parameters.

\section{Declarations}

\section{FUNDING}

This work was supported by Universidad Nacional del Litoral (Grant no. CAl+D2020 50520190100151LI), and the Agencia Santafesina de Ciencia, Tecnología e Innovación (Grant no. Res 94/21 CP-IO-201900011).

\section{COMPETING INTERESTS}

The authors have no relevant financial or non-financial interests to disclose.

\section{AUTHOR CONTRIBUTIONS}

Guillermo Ignacio Perez: Investigation; Data curation; Formal analysis; Validation; Visualization; Writing original draft; Writing - review \& editing. María Micaela Stoffel: Investigation; Validation. Claudio Javier Baroni: Investigation; Validation. María Eugenia Maina: Investigation; Validation. Lucas Damián Daurelio: Data curation; Formal analysis; Validation; Visualization; Resources; Supervision; Writing - review \& editing. Fernando Felipe Muñoz: Funding acquisition; Project administration; Conceptualization; Methodology; Investigation; Resources; Supervision; Writing - review \& editing.

\section{DATA AVAILABILITY STATEMENT}

The data that support the findings of this study are available on request from the corresponding author.

\section{SUPPLEMENTAL MATERIAL}

The supplemental material contains the figures where is presented the relations between the software programs for the parameters evaluated.

\section{COMPLIANCE WITH ETHICAL STANDARDS}

Each author confirms that the submitted manuscript has not been previously published and is not currently under consideration by any other journal. Furthermore, the authors have approved the contents of this manuscript and have agreed to the Plant and Soil 's submission policies. 
Fernando Felipe Muñoz https://orcid.org/0000-0001-6374-6676

Guillermo Ignacio Perez https://orcid.org/0000-0003-4338-8247

Lucas Damián Daurelio https://orcid.org/0000-0002-1156-2266

\section{References}

1. Arsenault JL, Poulcur S, Messier C, Guay R (1995) WinRHIZO ${ }^{\text {TM }}$, a Root-measuring System with a Unique Overlap Correction Method. HortScience HortSci 30: 906D-906. doi: 10.21273/HORTSCI.30.4.906D.

2. Atkinson D (2000) Root Characteristics: Why and What to Measure. In: AL Smit, AG Bengough, C Engels, M van Noordwijk, S Pellerin, SC van de Geijn (eds) Root Methods: A Handbook. Springer Berlin Heidelberg, Berlin, Heidelberg.

3. Atkinson JA, Pound MP, Bennett MJ, Wells DM (2019) Uncovering the hidden half of plants using new advances in root phenotyping. Current Opinion in Biotechnology 55: 1-8. doi: https://doi.org/10.1016/j.copbio.2018.06.002.

4. Balakhnina TI, Nadezhkina ES (2017) Effect of selenium on growth and antioxidant capacity of Triticum aestivum L. during development of lead-induced oxidative stress. Russian Journal of Plant Physiology 64: 215-223. doi: 10.1134/S1021443717010022.

5. Bucksch A, Burridge J, York LM, Das A, Nord E, Weitz JS, Lynch JP (2014) Image-Based HighThroughput Field Phenotyping of Crop Roots. Plant Physiology 166: 470. doi: 10.1104/pp.114.243519.

6. Delory BM, Schempp H, Spachmann SM, Störzer L, van Dam NM, Temperton VM, Weinhold A (2021) Soil chemical legacies trigger species-specific and context-dependent root responses in later arriving plants. Plant, Cell \& Environment 44: 1215-1230. doi: https://doi.org/10.1111/pce.13999.

7. Di Rienzo J, Casanoves F, Balzarini M, Gonzalez L, Tablada M, Robledo C (2008) InfoStat Versión 2011.

8. Feng R, Wei C, Tu S (2013) The roles of selenium in protecting plants against abiotic stresses. Environ Exp Bot 87: 58-68.

9. Griffiths M, Roy S, Guo H, Seethepalli A, Huhman D, Ge Y, Sharp RE, Fritschi FB, York LM (2021a) A multiple ion-uptake phenotyping platform reveals shared mechanisms affecting nutrient uptake by roots. Plant Physiology 185: 781-795. doi: 10.1093/plphys/kiaa080.

10. Griffiths M, Wang X, Dhakal K, Guo H, Seethepalli A, Kang Y, York L (2021b) Interactions among rooting traits for deep water and nitrogen uptake in upland and lowland ecotypes of switchgrass (Panicum virgatum L.).

11. Guo H, Ayalew H, Seethepalli A, Dhakal K, Griffiths M, Ma X-F, York LM (2020) Functional phenomics and genetics of the root economics space in winter wheat using high-throughput phenotyping of respiration and architecture. bioRxiv: 2020.2011.2012.380238. doi: 10.1101/2020.11.12.380238. 
12. Gupta M, Gupta S (2017) An Overview of Selenium Uptake, Metabolism, and Toxicity in Plants. 7. doi: 10.3389/fpls.2016.02074.

13. Haghighi M, Ramezani MR, Rajaii N (2019) Improving oxidative damage, photosynthesis traits, growth and flower dropping of pepper under high temperature stress by selenium. Molecular Biology Reports 46: 497-503. doi: 10.1007/s11033-018-4502-3.

14. Han E, Smith AG, Kemper R, White R, Kirkegaard J, Thorup-Kristensen K, Athmann M (2020) Digging roots is easier with Al. bioRxiv: 2020.2012.2001.397034. doi: 10.1101/2020.12.01.397034.

15. Handa N, Bhardwaj R, Kaur H, Poonam, Kapoor D, Rattan A, Kaur S, Thukral AK, Kaur S, Arora S, Kapoor N (2016) Chapter 7 - Selenium: An Antioxidative Protectant in Plants Under Stress. In: P Ahmad (ed) Plant Metal Interaction. Elsevier.

16. Hawrylak-Nowak B, Matraszek R, Pogorzelec M (2015) The dual effects of two inorganic selenium forms on the growth, selected physiological parameters and macronutrients accumulation in cucumber plants. Acta Physiol Plant 37: 1-13.

17. Himmelbauer M, Loiskandl W, Kastanek (2004a) Estimating length, average diameter and surface area of roots using two different Image analyses systems. Plant and Soil 260: 111-120. doi: 10.1023/B:PLSO.0000030171.28821.55.

18. Himmelbauer ML, Loiskandl AW, Kastanek AF (2004b) Estimating length, average diameter and surface area of roots using two different Image analyses systems. Plant and Soil 260: 111-120. doi: 10.1023/B:PLSO.0000030171.28821.55.

19. Hoagland DR, Arnon DI (1950) The water-culture method for growing plants without soil. College of Agriculture, University of California, Berkeley, Calif.

20. Irmak S (2017) Effects of Selenium Application on Plant Growth and Some Quality Parameters in Peanut (Arachis hypogaea). Pakistan journal of biological sciences : PJBS 20: 92-99. doi: 10.3923/pjbs.2017.92.99.

21. Kaur N, Sharma S, Kaur S, Nayyar H (2014) Selenium in agriculture: a nutrient or contaminant for crops? Archives of Agronomy and Soil Science 60: 1593-1624. doi:

10.1080/03650340.2014.918258.

22. Liu Q, Wang DJ, Jiang XJ, Cao ZH (2004) Effects of the Interactions Between Selenium and Phosphorus on the Growth and Selenium Accumulation in Rice (Oryza Sativa). Environmental Geochemistry and Health 26: 325-330. doi: 10.1023/B:EGAH.0000039597.75201.57.

23. Lobet G, Pagès L, Draye X (2011) A Novel Image-Analysis Toolbox Enabling Quantitative Analysis of Root System Architecture. Plant Physiology 157: 29. doi: 10.1104/pp.111.179895.

24. Lynch J (1995) Root Architecture and Plant Productivity. Plant Physiology 109: 7. doi: 10.1104/pp.109.1.7.

25. Lynch JM (1994) The rhizosphere - form and function. Applied Soil Ecology 1: 193-198. doi: https://doi.org/10.1016/0929-1393(94)90010-8.

26. Lynch JM, Brimecombe MJ, De Leij FA (2001) Rhizosphere. eLS. 
27. Mattupalli C, Seethepalli A, York L, Young C (2018) Digital imaging to evaluate root system architectural changes associated with soil biotic factors.

28. Mroczek-Zdyrska M, Wójcik M (2012) The influence of selenium on root growth and oxidative stress induced by lead in Vicia faba L. minor plants. Biological trace element research 147: 320-328. doi: 10.1007/s12011-011-9292-6.

29. Naseem M, Anwar-ul-Haq M, Wang X, Farooq N, Awais M, Sattar H, Ahmed Malik H, Mustafa A, Ahmad J, El-Esawi MA (2021) Influence of Selenium on Growth, Physiology, and Antioxidant Responses in Maize Varies in a Dose-Dependent Manner. Journal of Food Quality 2021: 6642018. doi: 10.1155/2021/6642018.

30. Osmont KS, Sibout R, Hardtke CS (2007) Hidden Branches: Developments in Root System Architecture. Annual Review of Plant Biology 58: 93-113. doi:

10.1146/annurev.arplant.58.032806.104006.

31. Pang W, Crow WT, Luc JE, McSorley R, Giblin-Davis RM, Kenworthy KE, Kruse JK (2011) Comparison of Water Displacement and WinRHIZO Software for Plant Root Parameter Assessment. Plant Disease 95: 1308-1310. doi: 10.1094/PDIS-01-11-0026.

32. Pound MP, French AP, Atkinson JA, Wells DM, Bennett MJ, Pridmore T (2013) RootNav: Navigating Images of Complex Root Architectures. Plant Physiology 162: 1802. doi: 10.1104/pp.113.221531.

33. Rogers ED, Benfey PN (2015) Regulation of plant root system architecture: implications for crop advancement. Current Opinion in Biotechnology 32: 93-98. doi: https://doi.org/10.1016/j.copbio.2014.11.015.

34. Seethepalli A, Guo H, Liu X, Griffiths M, Almtarfi H, Li Z, Liu S, Zare A, Fritschi FB, Blancaflor EB, Ma XF, York LM (2020) RhizoVision Crown: An Integrated Hardware and Software Platform for Root Crown Phenotyping. Plant Phenomics 2020: 3074916. doi: 10.34133/2020/3074916.

35. Seethepalli A, York LM (2020) RhizoVision Explorer - Interactive software for generalized root image analysis designed for everyone (Version 2.0.0beta1). doi: http://doi.org/10.5281/zenodo.3747698.

36. Shekari L, Kamelmanesh MM, Mozafarian M, Sadeghi F (2016) Beneficial Effects of Selenium on Some Morphological and Physiological Trait of Hot Pepper (Capsicum anuum). Journal Of Horticultural Science 29: 594-600. doi: 10.22067/jhorts4.v29i4.32110.

37. Tajima R, Kato Y (2011) Comparison of threshold algorithms for automatic image processing of rice roots using freeware ImageJ. Field Crops Research 121: 460-463. doi: https://doi.org/10.1016/j.fcr.2011.01.015.

38. Tajima R, Kato Y (2013) $\square$ Short Report $\square A$ Quick Method to Estimate Root Length in Each Diameter Class Using Freeware ImageJ. Plant Production Science 16: 9-11. doi: 10.1626/pps.16.9.

39. Wang M-B, Zhang Q (2009) Issues in using the WinRHIZO system to determine physical characteristics of plant fine roots. Acta Ecologica Sinica 29: 136-138. doi: https://doi.org/10.1016/j.chnaes.2009.05.007.

\section{Figures}



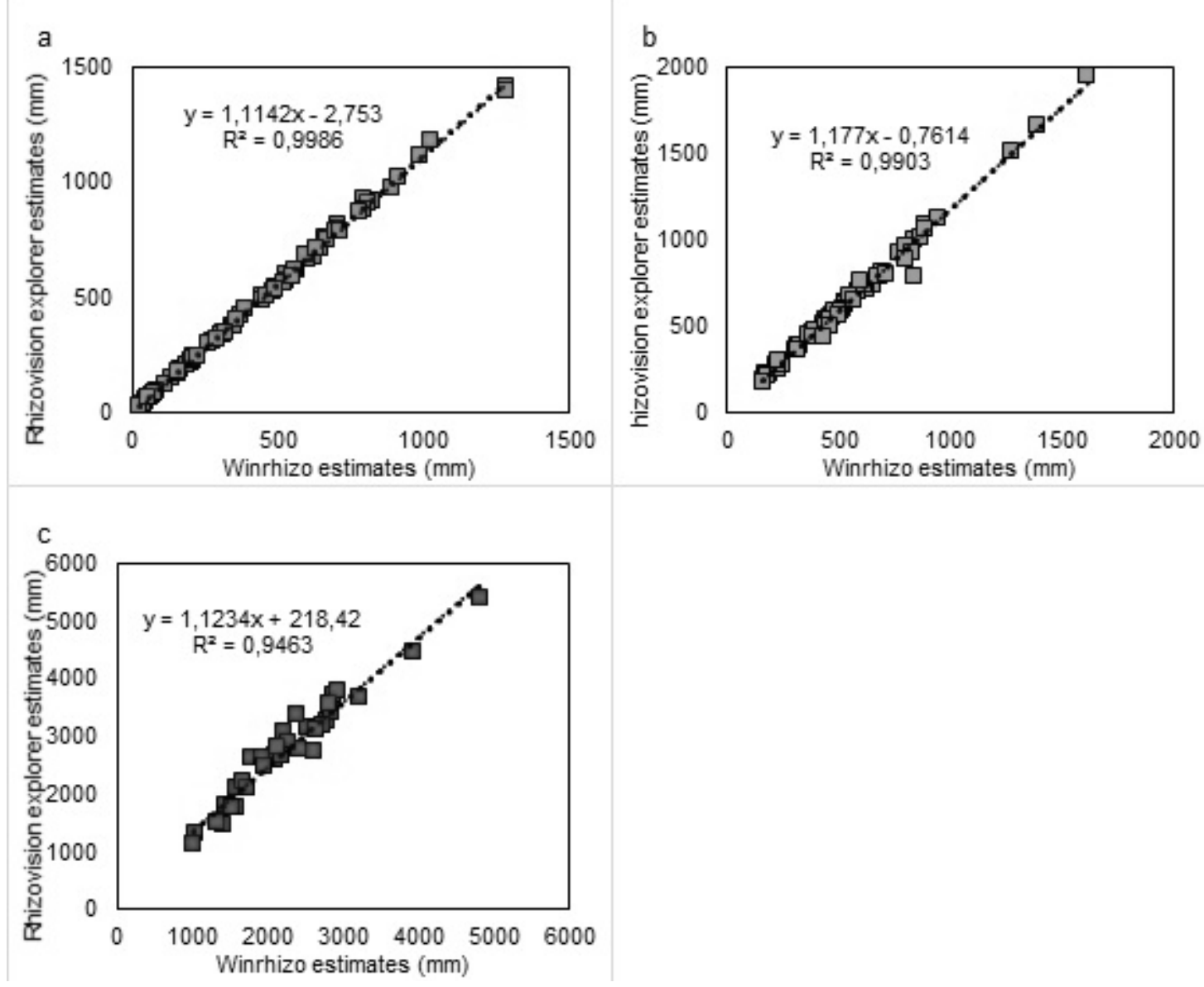

\section{Figure 1}

Comparison between RhizoVision Explorer and WinRhizo for total root length $(\mathrm{mm})$. A linear regression model is fit for lettuce (a), broccoli (b) and bell pepper (c). The dotted black line represents the linear regression line 

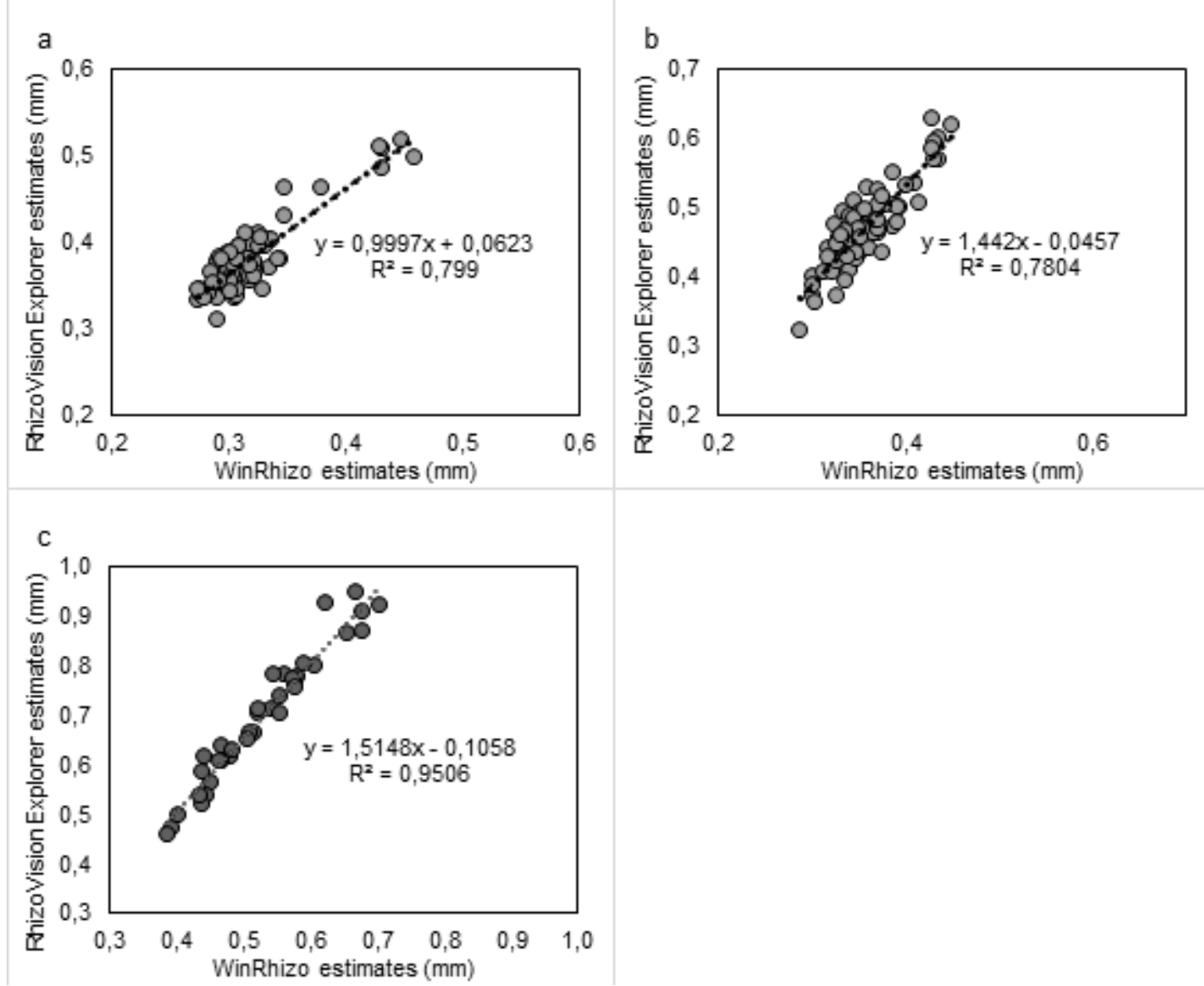

\section{Figure 2}

Comparison between RhizoVision Explorer and WinRhizo for average diameter $(\mathrm{mm})$. A linear regression model is fit for lettuce (a), broccoli (b) and bell pepper (c). The dotted black line represents the linear regression line 

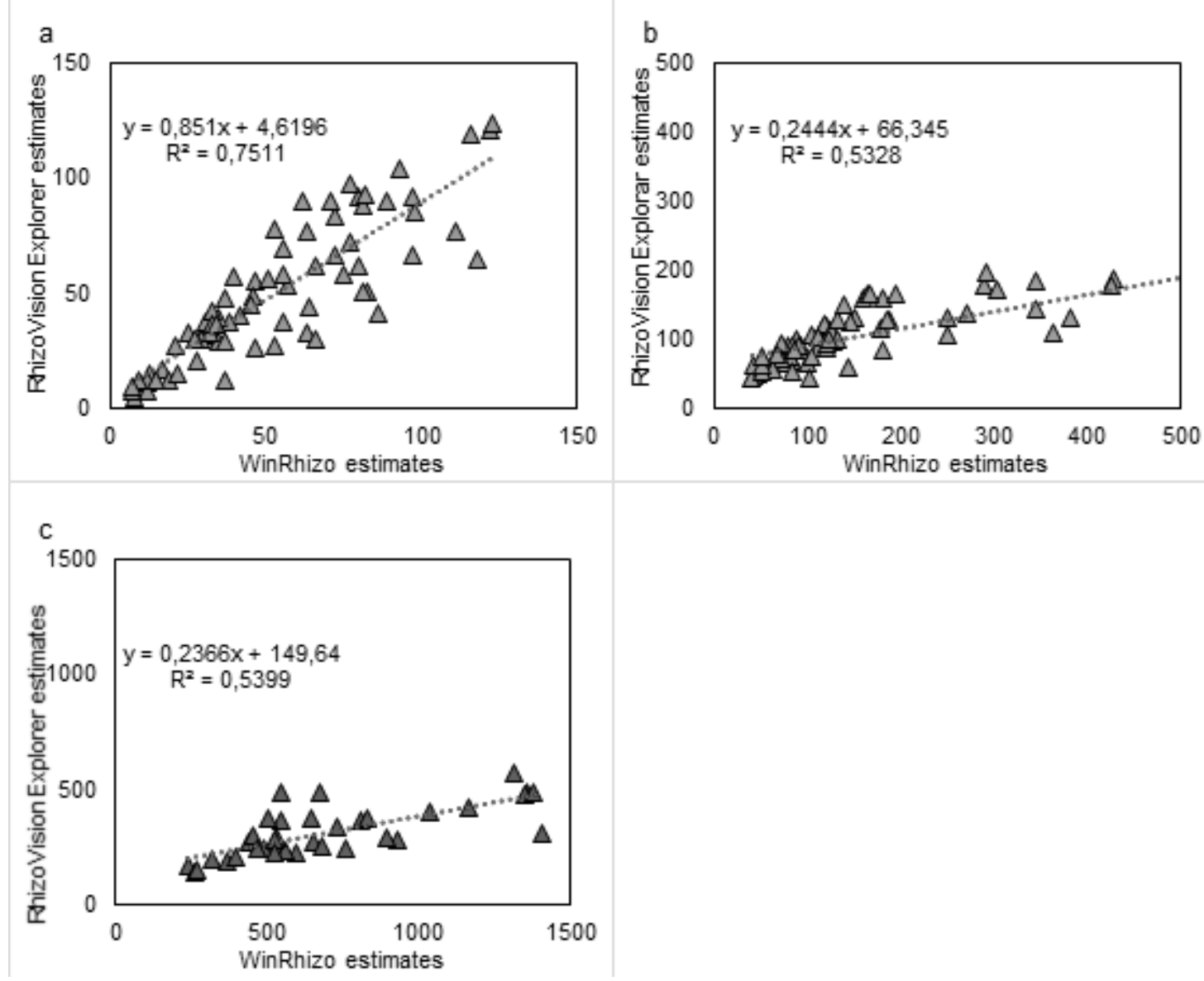

\section{Figure 3}

Comparison between RhizoVision Explorer and WinRhizo for root tips number. A linear regression model is fit for lettuce (a), broccoli (b) and bell pepper (c). The dotted black line represents the linear regression line 